\title{
Investigating Mobile Devices Integration in Higher Education in Cyprus: Faculty Perspectives
}

\author{
doi:10.3991/ijim.v3i1.762 \\ N. Eteokleous1, and D. Ktoridou ${ }^{2}$ \\ ${ }^{1}$ Frederick University Cyprus, School of Education, Nicosia, Cyprus \\ ${ }^{2}$ University of Nicosia,School of Business, Nicosia, Cyprus.
}

\begin{abstract}
Mobile devices are everywhere and mobile learning has emerged as a potential educational environment; however it is relatively new to Cyprus educational system. The purpose of this research work is to assess and determine the readiness; and evaluate the viability of integrating mobile technology in Cyprus higher education level. To address the above, a mixed method approach is employed making use of quantitative and qualitative data from faculty members working in three private universities in Cyprus. Faculty reactions were mixed with some of them seeing the benefits for mobile learning while others have doubts. The results summarize the technological and pedagogical aspects to be considered prior integrating mobile devices. Additionally, the study supports that one of the major barriers to educators is the lack of understanding regarding mobile devices integration in the teaching and learning process. Finally, there is a need to develop well-defined and well-structured requirements for mobile integration in the classroom.
\end{abstract}

Index Terms-mobile devices, higher education, faculty perspectives, technological \& pedagogical aspects

\section{INTRODUCTION AND THEORETICAL FRAMEWORK}

The walls of the classrooms are torn down. Computer technology evolution has widened the educational activities for instructors and students in the 90's, removing time and space constraints from instructors as well as from students themselves. With the rapid diffusion of the Internet, computers, and telecommunications; new approaches to learning were created [4]; [12]; [27]. Online courses appeared as a new method of course delivery. Since then, the interest in the development and use of distance learning in higher education has been steadily increasing [14]. The demands of e-learning on one hand, in connection with the possibilities offered by modern technology (i.e. evolution of mobile devices) on the other hand, pose new opportunities and new challenges to the educational systems [30]; [47].

More specifically, during the past decade every area of education and training has been affected by the introduction and use of technological advancements. Elearning (electronic learning) originated from D-learning (distance learning) and now, the follow-up is M-learning (mobile learning). As latest models of mobile phones combine PDA functions with cameras, video and MP3 players, m-learning becomes more convenient and exciting. The process of adding mobility to interactivity transformed the role of the Internet and has set new beginnings to innovations, services and applications. This new learning environment supports collaborative and accessible learning experiences for both instructors and learners that are integrated anytime and anywhere beyond the classroom [30]; [47]

\section{A. M-Learning}

$\mathrm{M}$-learning can be defined as e-learning using mobile devices and handheld IT devices, such as PDAs or Personal Digital Assistants (e.g. Palm, Pocket PC), mobile phones, laptops, tablet $\mathrm{PC}$ technologies and smart phones (e.g. Blackberry, iPhone) with wireless networks; digital media players (e.g. iPods, MP3 players), intelligent active badges and portable game devices [3]; [20]; [27]; [42]. Some view e-learning as the immediate ancestor of $\mathrm{m}$ learning. E-learning is defined as learning supported by digital electronic tools and media, and, by analogy, mlearning is defined as e-learning that uses wireless transmission and mobile devices such as PDAs, mobile phones, laptops and tablet PCs [32]; [41]; [47]. Along the same lines, the eLearning Guild Report supports that "mobile learning is a subset of e-Learning, yet it has its own distinctive, expensive, and restrictive qualities" [33, p. 1]. In agreement, Evans mentions that "m-learning inherits the advantage of e-learning, but extends their reach making use of portable wireless technologies" [20, p.492]. In Quinn's study it is defined simply as learning that takes place with the help of mobile devices [38]. Turunen, Syvaenen and Ahonen view mobile devices as a pervasive medium that may assist us in combining work, studying and leisure time in meaningful ways [45]. Polsani considers these definitions 'restrictive' and proposes instead the term 'network learning' (or ' $n$ learning'). He defines mobile learning as a form of education whose site of production, circulation, and consumption is the network [37].

Mobile technology integration has already started. Mobile learning (m-learning) has emerged as a potential educational environment to support learning as well as to increase the quality of learning with proper use [27]. Mobile tools immerse in the learning context and surround the educators, the students and the environment they operate. Some are purely assistive and supportive in nature and others are becoming increasingly intelligent. These tools can be directly integrated in classroom activities in order to enhance and promote new ways of teaching and learning. Mobile learning allows instructional designers and instructors to utilize the strengths of mobile platforms to bring a variety of new applications to the learning environment [3]; [27]; [29]; [35]; [48]. 


\section{B. Mobile Devices Integration}

Mobile devices are everywhere, and various innovative practices and experiments took place in all levels of education from elementary to higher education (formal education) as well as to informal and non-formal educational settings [3]; [29]. Research studies appear to report positive and encouraging results [2]; [3]; [15]; [16];[20];[22];[27];[30];[35];[42]; [44]; [47]. Examples of mobile devices integration can be found in various countries across the globe, mainly in colleges and universities in Europe, and the USA [27];[33];[47]. As the eLearning Guild Report supports "colleges and universities have taken the lead in mobile learning adoption" and "have been among the early adopters of mobile learning" [33, p. 5].

Mobile wireless computers, mobile wireless phones and PDAs are the ones mostly used in higher education [27];[47]. Based on various research studies, we suggest that mobile use can be categorized based on the following parameters: 1) educational level (e.g. primary, secondary or higher level); 2) educational setting (e.g. informal, formal); 3) purpose of use (e.g. learning and teaching purposes, organization and administration purposes, research purposes); 4) person using the device (e.g. the educator/instructor, the student; 5) location of use (e.g. in classroom, at the library, outdoor activities - arts and science centers, museum and field trips) [3];[20];[27];[29]; [35];[47]. Each mobile use has various characteristics, for example it could be used at the secondary level, by the teacher for administration purposes in classroom. Based on the category "person using the device", find below a summary of how students and educators use mobile devices for numerous purposes. First of all students, use mobile devices for notes taking, and homework completion; conducting research and classwork anywhere anytime; podcasting revision; collecting, organizing, and exchanging data (e.g. send and receive library data, exchange e-books through beaming).

Additionally, they use mobile devices as communication tools, graphing calculators, and mapping concepts creators [3];[20];[27];[29]; [35];[47]. Educators take advantage of mobile devices mainly for three purposes: teaching and learning; administration and organization; and research purposes. Regarding teaching and learning purposes, mobile devices are used for quizzes, in-class tests, and language instruction; to share syllabi, lectures' schedules, lesson materials, notes, images and photos; and provide web-based curriculums. As far as it concerns administration and organization purposes, mobile devices uses are summarized as follows: manage data such as classes schedule, students' grades and attendance' organize courses, lecture material, student assignments, and exams as well as access central school data. Finally, for research purposes mobile devices are used as performance and decision support tools, to gather and analyze data as well as to manage research results and information [3];[20];[27];[29]; [35];[47].

Several advantages and educational benefits were reported regarding mobile devices integration. The above can be summarized as mobility, easy of movement and use, flexibility, functionality, convenience, simplicity, speed, affordability, economic/ cost benefits, information management capacity, and share information instantly. Additionally, mobile devices use improves efficiency and effectiveness in teaching and learning, enables one to one learning, enhances private and self-constructed/ self-paced learning and independent work, improves communication and collaboration among faculty members and students, promotes inquiry-based investigation, improves interpersonal communications and social interactions, accommodates students' needs, and finally increases productivity, performance, and learners' access [3];[20];[27];[29];[33];[35];[47]. The major concerns or in other words drawbacks of m-learning mentioned in various studies are the following: security, limited bandwidth and capacity, small screen size, technical and design obstacles, as well as pedagogical concerns such as the complexity in how mobile devices support meaningful learning [3];[27].

Based on the above, the pictorial in Figure 1 represents and explains a learning environment where mobile devices are integrated, as well as the relationship among the learner, the instructor and the academic community. The learner and the instructor are considered to be the center of this m-learning environment within the academic community. All three parties are influenced by the following key issues:

- Underlying principles for implementing mobile learning technologies: the major issue for a successful implementation is to develop welldefined and well-structured requirements.

- Effects of ubiquitous access to a WLAN change on insight and outside the classroom learning: insight the classroom, mobile learning offers lecturers and learners increased flexibility and new opportunities for interaction. M-Learning allows a collaborative and accessible learning experience that integrates with the world beyond the classroom.

- Best practices for using mobile learning: developing and delivering mobile learning is a new practice, yet is a question how much of what people are doing constitutes best practice. The focus and attention must be on the development, distribution, and adoption of best-practices for mobile learning [33].

- Provision of best end-user support for mobile learning: The issue of end-user support is of major importance for m-learning integration. The lecturer as well as the student must be provided with the best support. The academic society must be well equipped to handle any questions and problems from an extensive peer-to-peer on campus support group.

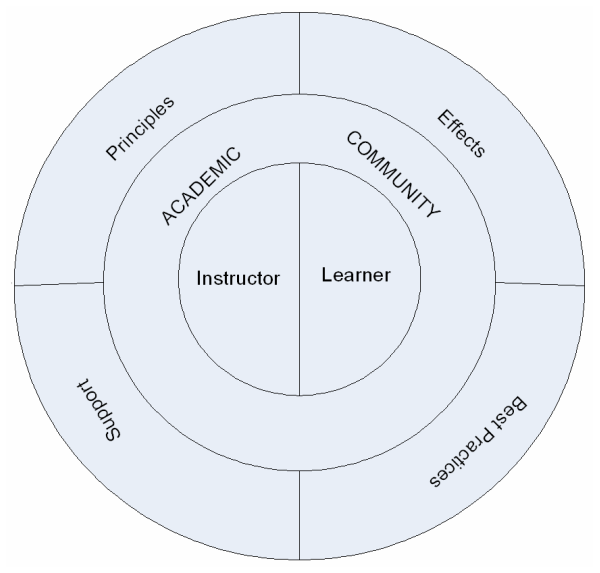

Figure 1. Learning environment 


\section{Current Situation in Cyprus Higher Education}

Cyprus is the third biggest island in the Mediterranean sea, situated in the crossroads of three continents: Europe, Asia and Africa [18];[46]. The context of this study is Cyprus higher education level, that can be characterized as a newly established field, since Cyprus did not have a public university until 1992 [18];[46] even though other higher education private and public institutions have been established and operating in the island for too many years [13]; [18]. More specifically, the development of Cyprus higher education officially started in the late 80 s "where the establishment of the Department of Higher Education within the Ministry of Education in 1984 gave the momentum needed for the field to develop" [18, p. 3]. The Department of Higher and Tertiary Education of the Ministry of Education and Culture (MOEC) is responsible for Third-level education. More specifically, Cyprus educational system is centralized and the highest authority for educational policy making is the Council of Ministers [18];[25].

As of now higher education is provided in three different types of institutions, i.e. public and private, universities, public tertiary institutions, and private higher institutions (colleges). The private universities (previously were operating as private colleges) began their operation in September 2007. Overall, in Cyprus there are three public and three private universities, there are eight public higher institutions, and there are also twenty-three private third-level education schools, colleges and institutes [10];[18];[25];[36].

\section{Technological Advancements and Technology Integration in Cyprus Educational System}

Cyprus is regarded as a developing nation and not that technologically advanced nation [46]. However, in the past couple of years, various technological developments and expansions in the areas of telecommunications, broadcasting, third generation (3G) networking technology, broadband wireless networking, GSM network and satellite technology; provided the appropriate foundation and infrastructure for the enhancement and promotion of technology integration in education.

The use of technology in Cyprus educational system was limited during the years of 1960s to 1980s, "to the use of traditional audiovisual equipment and some government produced educational radio and television programming" [46; p. 125]. The official and at the same time advanced technology integration in Cyprus educational system took place in the early 1990s, mainly in primary education. The launch of an ICT policy by the Cypriot MOEC, gave the momentum to technology integration to flourish in education. Some primary schools were equipped with computers at an experimental level. Also, a Departmental IT group was created as a part of the Department for Programs Development of the MOEC, while the governmental Pedagogical Institute started offering at the end of the 1990s an optional training program for teachers. 'Evagoras' (1999) was the first formal ICT policy document, and describes the action plan for the embedding of new technologies in primary education from 2000 to 2005 [17]. Schools were connected to the Internet and equipped with computer labs; and classrooms were equipped with few computers. Regarding secondary education, there is no clear-cut policy to integrate technology as a tool in the classroom.
However, access to technology was given to all secondary schools by being connected to the Internet and equipped with computers labs. Additionally, information technology and computers classes were introduced in the secondary education curriculum. The infrastructure and equipment give the opportunity to the teachers to use computers in all areas of the curriculum [39]. As far as it concerns higher education, even though it is under the control of the MOEC (see above), the institutions have the flexibility to develop their own agenda regarding technology use. High speed Internet connection, network capabilities, high-end computer labs, provision of desktop computers and laptops to faculty members as well as in some cases to students (i.e. Frederick University Cyprus) highlight the situation in Higher education institutions.

Various empirical studies examined computer technology integration in Cyprus educational system in all levels; primary, secondary and higher education [1]; [17]; [23]; [26]; [46]. The same does not exist regarding mobile devices integration since attempts to integrate them mainly focuses on primary and secondary education. An example of the above is called HandLearn and it "aimed at investigating the use of handheld computers within the context of elementary school science" [3, p. 358]. Although, the global interest has been growing and proceed to various attempts in integrating mobile devices in higher educational settings [16];[20]; [27]; [35]; [47], there were no attempts to integrate mobile devices in Cyprus higher education.

More than $90 \%$ of public universities and $80 \%$ of private universities in the US are using at some level wireless technologies [42]. Given the above, one of the most important challenges that Cyprus higher education has to face is to effectively and efficiently integrate mobile devices in its practices in order to follow the global trend. As Kim and Holmes mention "the movement of mobile devices wireless technologies in education is a recent trend, and it is now becoming the hottest technology in higher education" [27, p.78].

Many of the studies that examined mobile devices integration in various educational systems and countries [2]; [3];[15];[16];[20];[22];[27];[29]; [35];[42][44];[47] appear to report positive and encouraging results. However, the successful stories and the innovations occurred at a localized level having minimal impact [21] and consequently they have not been scaling up. Why the above happens? Are we moving too fast towards integrating mobile devices into current educational setting and activities? [19] Has the readiness of the educational systems to accept and support mobile devices integration been addressed? Is faculty willing to integrate mobile devices in their classroom practice? Does faculty posses the necessary technological literacy, skills and abilities in order to integrate mobile devices in their educational practices? What organizational, educational and personal factors might influence mobile technology integration in classrooms? Harnessing mobile technologies and putting them in the true service of learning is not going to be an easy task. Through critical consideration and evaluation of experiences gained during the computer technology integration, online and e-learning, it is crucial to be proactive, make educated and conscious decisions, avoid mistakes of the past and take full advantage of the experiences, lessons learned and effective practice guidelines [33]; [47]. 
Given the above, the literature lacks of academic research on assessing the needs and demands from technical and pedagogical perspectives before integrating mobile devices in the educational settings [30]. Even though mobile devices integration has been examined mainly in developed countries, the literature lacks on studies from developing countries, without much experience using mobile devices for higher education, which although have the appropriate equipment and infrastructure, such as Cyprus.

In order to be able to meet and follow the pressures of global competition in a knowledge-based, net-centric new economy, as well as apply the new trends and innovations in education, and experience these innovations in our system; Cyprus's educational leaders should increasingly consider mobile devices integration in their practices. This paper focuses on examining the readiness of higher education context in integrating mobile devices. Specifically, the perceptions of higher education lecturers as well as the challenges that should be taken into consideration by the higher educational institutions for the realization of this integration into their educational practices [7]; [43].

\section{MAIN AIM AND RESEARCH OBJECTIVES}

The purpose of this research work is to assess and determine the readiness; and evaluate the viability of integrating mobile technology into the teaching and learning processes in higher education in Cyprus. More specifically, it explores faculty perceptions regarding mobile technology integration and identifies their willingness to integrate mobile devices in their classroom practices. In addition, it attempts to identify the factors such as organizational, educational, and personal that influence mobile technology integration in higher education. Finally, the proposed study aims in defining and delineating the technological and pedagogical aspects to be taken into consideration for successful mobile technology integration. Examining the innovation through faculty perspectives is a good starting point since they are one of the most important "players" in mobile devices integration. Since, mobile integration has not yet started in Cyprus it is extremely valuable to consider various parameters in advance in order to achieve a successful integration of mobile devices.

The paper has both practical and theoretical significance and contribution. The practical significance of the paper lies in the fact that it can provide guidelines and recommendations to countries that are interested or planning to implement mobile learning. The practical value of the paper goes beyond the borders of Cyprus since it aims to develop a set of directions and guidelines of mobile learning in an educational system. More specifically, the paper is of great importance for the design and planning of mobile learning integration in developing countries, such as Cyprus, where the technological infrastructure exists, although lacking experience on this kind of integration. Besides the above, it could be valuable for educational system and countries that already using mobile devices to take corrective actions and address any problems appeared. Furthermore, the study adds to the current body of literature since it assesses the readiness of an educational system, to integrate mobile learning; and literature lacks of this kind of studies [33]. Along the same lines, the paper differs from other studies conducted related to mobile learning, since those investigated specific mobile practices and applications (e.g. how mobile devices have been integrated, their effectiveness, and contribution to the learning environment). However, this study is conducted on a broader level besides the boundaries of a classroom or an institution. Additionally, the results of the study provide the foundation of examining the feasibility of mobile integration in other formal, non-formal or informal educational settings, countries and levels. There are not yet many studies that investigate the feasibility of mobile devices integration through identifying the requirements needed for successful integration. Consequently, it stimulates further research to be conducted in the field. Besides the above, this field is relatively new and studies regarding mobile integration are still rare in Cyprus. Also, the mixed results of the paper could promote debates in various educational settings and levels. Finally, it consists of the foundation of the development of a framework of guidelines and suggestions in systemically integrating mobile devices integration in an educational system.

\section{RESEARCH METHODOLOGY}

To address the above a mixed method approach was employed [11]; [28]. The study made use of both quantitative and qualitative data. To better 'use' the data gathered the study applied a sequential explanatory strategy where first the quantitative data were collected and analyzed and then the qualitative data collection and analysis followed. The two methods were integrated during the interpretation phase of the study.

The research population consists of private universities faculty members. The quantitative component was addressed through a survey administered to a sample of private college faculty members. A survey was considered the most appropriate method since it enabled the researchers to collect data from a wide range of faculty. Additionally, the survey provided the opportunity to capture an initial picture of faculty perspectives regarding mobile technology integration in education as well as identify the factors that might influence mobile devices integration.

Quantitative data were collected through questionnaires. The survey sample selection was based on purposive sampling in an attempt to get faculty members with various characteristics such as age, fields of teaching, educational background, as well as computer and mobile literacy level. The questionnaires were circulated among 200 faculty members in three private universities in Cyprus. The response rate was $60 \%$ since, 120 faculty members completed and returned the questionnaires. The current research work does not aim to generalize the findings rather than evaluate the feasibility of mobile devices integration by identifying the aspects needed for successful integration from faculty members' point of view.

The phenomenological approach was applied in order to address the qualitative part of the current study. Phenomenological research was used to understand the experiences of other people and the meaning they make of that experience [34]. It requires that researchers put aside their opinions and egos and focus on the worth of the stories of those individuals who we are interviewing. This approach assisted in the construction of semi-structured, open ended questions that encouraged the participants to 
use their own terminology to describe their own experiences and perceptions on the subject under investigation.

Purposive sampling was used in an attempt to draw the subjects for the interviews. More specifically, a subsample of those faculty surveyed were selected to participated in the interviews. Twenty participants were chosen to be interviewed (See Table 1) based on their fields and their responses at the questionnaires. The interviews provided the opportunity to explore faculty perception on various parameters related to mobile devices integration. More specifically, the subsequent interview protocols, aimed at providing a deeper level of data that were used to evaluate, confirm, complement and/or better understand the survey findings [31]; [40]. Interviews took place as soon as the quantitative analysis ended.

TABLE I.

INTERVIEW PARTICIPANTS FROM EACH FIELD

\begin{tabular}{|l|c|c|}
\hline \multicolumn{1}{|c|}{ Field } & N & \% \\
\hline Sciences and Engineering & 8 & $40 \%$ \\
\hline Business & 3 & $15 \%$ \\
\hline Arts and Languages & 4 & $20 \%$ \\
\hline Education & 5 & $25 \%$ \\
\hline Total & $\mathbf{2 0}$ & $\mathbf{1 0 0 \%}$ \\
\hline
\end{tabular}

\section{DATA ANALYSIS \& RESEARCH OUtCOMES}

\section{A. Quantitative Data Analysis}

The questionnaire was divided into the following four parts: a) background information, b) technology and mobile learning literacy, c) current mobile devices integration in teaching and learning process, and d) potential for future integration of mobile devices. The purpose of the first part of the questionnaire was to identify the demographic information and the academic background of the respondents. This information served as the basis for the analysis of the replies to the other parts of the questionnaire. Based on the responses to the questions in the first part of the questionnaire four broad categories of faculties were revealed: sciences and engineering, business, arts and languages, and education.

Concerning the general knowledge on mobile learning, it has been observed that faculty of sciences and engineering were more knowledgeable of mobile technology in general and, more specifically, of mobile learning. The group with the least degree of awareness in mobile technology and learning was that of business. The findings are summarized in Table 2.

TABLE II.

FACULTY's GENERAL KNOWLEDGE ON MOBILE TECHNOLOGIES AND LEARNING

\begin{tabular}{|l|c|c|}
\hline Faculties & Yes & No \\
\hline Sciences and Engineering & $63 \%$ & $37 \%$ \\
\hline Business & $17 \%$ & $83 \%$ \\
\hline Arts and Languages & $20 \%$ & $80 \%$ \\
\hline Education & $50 \%$ & $50 \%$ \\
\hline
\end{tabular}

It was also revealed that even though the participants had a general idea on mobile technologies and learning, they lacked the expertise to implement it as a tool for their classes. When it comes to using such technology, the responses indicated that none of the respondents is utilizing this tool.

As far as the potential of future mobile integration in higher education learning is concerned, a broad quantification of the results led to the findings summarized in Table 3. Obviously, the potential was higher for faculty in Sciences and Engineering which was not surprising as they were more comfortable with the advancements of new technologies.

TABLE III.

POTENTIAL FOR FUTURE MOBILE DEVICES INTEGRATION

\begin{tabular}{|l|c|c|c|}
\hline \multicolumn{1}{|c|}{ Faculties } & Low & Medium & High \\
\hline $\begin{array}{l}\text { Sciences and } \\
\text { Engineering }\end{array}$ & & & $\mathrm{X}$ \\
\hline Business & & $\mathrm{X}$ & \\
\hline $\begin{array}{l}\text { Arts and } \\
\text { Languages }\end{array}$ & $\mathrm{X}$ & & \\
\hline Education & & $\mathrm{X}$ & \\
\hline
\end{tabular}

The very last part of the questionnaire engaged in identifying the factors that might influence educators' usage of mobile devices in the classroom. As shown in Table 3, more important appeared to be 1) the need for professional development and training in integrating mobile devices into classroom activities and 2) the lack of knowledge and skills in integrating mobile devices into classroom activities. Similarly, less important factors proved to be the lack of campus-wide wireless network, and the lack of time to study for integration (See Table 4).

TABLE IV.

RANKING OF IMPORTANCE OF VARIOUS FACTORS THAT MIGHT INFLUENCE EDUCATORS’ USAGE OF MOBILE DEVICES

\begin{tabular}{|l|c|}
\hline \multicolumn{1}{|c|}{ Factor } & $\begin{array}{c}\text { Ranking in terms } \\
\text { of importance }\end{array}$ \\
\hline $\begin{array}{l}\text { Personal attitude towards mobile technology } \\
\text { integration regarding their use in the } \\
\text { classroom activities }\end{array}$ & 3 \\
\hline $\begin{array}{l}\text { Level of mobile devices literacy - knowledge } \\
\text { and skills in using mobile devices for any } \\
\text { purposes (not only educational/in classroom) }\end{array}$ & 3 \\
\hline $\begin{array}{l}\text { Lack of knowledge and skills in integrating } \\
\text { mobile devices into classroom activities }\end{array}$ & 1 \\
\hline $\begin{array}{l}\text { Need for professional development and } \\
\text { training in integrating mobile devices into } \\
\text { classroom activities }\end{array}$ & 1 \\
\hline Lack of time to study for integration & 5 \\
\hline Lack of campus-wide wireless network & 5 \\
\hline $\begin{array}{l}\text { Lack of technological resources (software } \\
\text { and hardware) }\end{array}$ & 2 \\
\hline $\begin{array}{l}\text { Use of mobile technology may sometimes } \\
\text { lead to pitfalls }\end{array}$ & 3 \\
\hline
\end{tabular}

\section{B. Qualitative Data Analysis}

1) Wireless and mobile technologies in education: Technological aspects

This section addresses the types of technologies currently available for m-learning, and discusses the benefits and limitations of their integration. The authors presented and explained the following available mobile technology devices to the participants. It was necessary to gain some initial knowledge of what the mobile devices look like and what they can offer in order to be able to 
further discuss the technological and pedagogical aspects to be considered:

SMS: Short Message Service allows users to send/receive messages of up to 160 characters between mobile phones (text messaging).

MMS: Multmedia Messaging Service serves the same purpose as SMS but allows the inclusion of graphics. Mobile Learning software: Specifically designed learning modules using m-learning software.

Wireless access points WAPs: There are two popular wireless standards, wireless fidelity - Wi-fi, also known and Bluetooth. Wi-fi is used primarily for Internet access.

GPRS: (General Packet Radio Service): In Wikepedia article this mobile data service is available to users of specific phone types. It can be used for WAP service, SMS, MMS, email, and access to the World Wide Web.

Bluetooth: a short-range wireless connection between PCs, handhelds, PDAs, mobile phones, camera phones, printers, digital cameras, e.t.c. It uses Radio Frequency (RF) for communication with the possibility of secure communication between multiple devices within a 30 -foot range.. Bluetooth technology uses a globally available frequency band $(2.4 \mathrm{GHz})$ for worldwide compatibility.

$3 G$ and $4 G$ phones: $3 G$ technologies enable network operators to offer users services: wireless voice telephony, video calls, and broadband wireless data, with data transmission capabilities able to deliver speeds up to $14.4 \mathrm{Mbit} / \mathrm{s}$ on the downlink and $5.8 \mathrm{Mbit} / \mathrm{s}$ on the uplink. By the end of the decade 4G (4th Generation mobile phones) will provide up to 100 megabits per second transmissions adequate for multimedia.

PDAs: Personal Digital Assistants, usually called a pocket PC, which can store documents, spreadsheets, calendar entries, games, databases, and lots of other resources normally associated with a laptop or desktop computer using the Palm OS or MS Pocket PC operating system. PDA's are relatively inexpensive, highly portable, and are designed to utilize small, low-bandwidth files and applications.

MP3s: Audio file format that efficiently compresses files and enables them to be shared.

CAMs: Video cameras now embedded into mobile phoneand PDAs.

Given the above descriptions and presentations, the participants were asked to comment on the benefits and limitations of mobile devices integration in education, mainly from a technological aspect of view. The limitations of m-learning devices given by the participants are delineated below. The following limitations were mainly discussed by the faculties from the Sciences and Engineering fields, without implying that the rest of them did not contribute to this part. The small screens of mobile phones and PDAs, the limited storage capacities in PDAs and the battery life/charge were the three limitations discussed by almost all of the participants. The lack of common operating system and common hardware platform makes it difficult to develop content for all. As all of the technology devices can become out of date quickly and for some of them there is limited potential for expansion with some devices. Another two limitations reported were the difficulty that still exists in using graphics and the difficulty with printing, unless connected to a network. Finally, the limited wireless bandwidth that may degrade with a larger number of users and the concerns about security issues were also reported from the participants.

The benefits reported were grouped in two categories the technology-oriented and the pedagogy-oriented ones. The most important technological benefits reported were the following.

1. Portability: The ability for the lecturer and the learner easily to move with a device inside a learning environment or to different learning environments.

2. Cost Effectiveness: Handhelds are becoming more affordable and therefore accessible to students. Additionally, the majority of the students own devices like that.

3. Accessibility: Easy access to mobile devices, even though students might be in different locations as well as equal access for learners with disabilities.

4. Convenience: Students can have access to content including theoretical information, quizzes, journal entries, balance sheets, learning games from anywhere.

5. Ownership - Increase motivation: Since students own their devices they are motivated to use them and learning from it.

The pedagogical benefits were summarized in three main categories: students' collaboration, interaction, and increased involvement:

1. Collaboration: Students can learn best when they share with each other and get immediate instructions and feedback

2. Interaction: Student can interact with instructors and among each other effectively and easily.

3. Increased involvement: The new generation likes mobile devices such as PDAs, phones and games devices, so they feel more motivated and interested in using them.

2) Pedagogical aspects - Learning with Mobile Technologies

This part of the paper discusses how mobile technologies can be used, and the various issues to be taken into consideration before integrating mobile devices as tools in the educational practices.

Two approaches of mobile devices integration were mostly discussed: 1) as a supportive tool; and 2) as an instructional tool. The approaches discussed below were mostly recommended and argued by the educators from the engineering and computer sciences fields; without implying that the rest of the participants did not address this question. Two of the educators reported having the experience of using mobile devices in their teaching practices. The educators argued that as supportive tools mobile devices allow the recording and maintenance of the lessons, the instructional procedures, the type of mentoring and the pedagogical approach, the role of the teacher and students. Additionally, the educators supported that mobile devices can facilitate communication between faculty members and students. More specifically, one of them mentioned that the above can be achieved "...through file sharing capabilities, builtin networking and a friendly interface with on-line 
discussion and e-mail options". Additionally, the educators reported that mobile devices can be used as instructional tools to support constructive learning [48]. Educators can provide students with electronic books, school-specific context, internet reference sites, graphing calculator, dictionary, and thesaurus etc. Finally, "...electronic quizzes and tests can be taken through mobile devices", as one of the participants argued. Educators from the Business and Arts and Languages Field revealed to be sceptical towards using mobile technologies as instructional tools.

Concerns and issues to be taken into account were discussed by all of the participants, include: the lack of knowledge regarding mobile devices integration, the need for skills development in successfully implementing mobile devices in teaching practices, the need for appropriate learning materials, instructional approaches and strategies to be applied, and educators' professional development programs specifically designed for this purpose. The above issues are further discussed below.

All of the participants seemed to agree that the new mobile learning arena imposes significant new design requirements of the curriculum per se. These requirements are not limited to the ways in which it is delivered and received but moreover in the ways the curriculum is structured and the ways in which it is maintained. A participant discussed the need for the "...curriculum units to be project-based, including a well-defined pedagogical and technological angle". The majority of them mentioned that the activities within the curriculum can be designed to take place in classroom (deskwork) or mainly outside the classroom (fieldwork).

Given the fact that the participants got an initial idea of what mobile devices are and what capabilities they have, participants were asked to think of examples of using mobile technology in the courses they were teaching during that time. They were instructed that by completing this activity the students should reach a number of educational objectives. Amazingly, all of them managed to briefly describe a lesson from the courses they teach where they could integrate mobile technology. Even the sceptical ones managed to describe either a game or an activity to take place in their lessons. One of them also argued that... "It is unrealistic to support that mobile devices could be used for all classroom activities". Another one came up with the idea of using mobile technology to evaluate students learning as well as assess students' attitudes to learning.

Some of the participants from the Arts and Languages and Education Fields expressed their concerns that mlearning technologies might support individualism. On the other hand some others said that it can facilitate the application of constructivist techniques where collaboration and team work can be enhanced and promoted [48].

All of the participants strongly commented on the need of professional development training programs to be designed for this specific purpose. "We all use mobile devices for calls, to send messages, for calendar and reminder purposes, but it is a totally other issue using them for teaching and learning purposes", one of them said. The participants agreed that they have to be trained on how to use mobile technology as an instructional tool.
All of the participants strongly argued that they should be involved throughout the entire process of designing, developing and implementing mobile technology integration. Being directly and actively involved, the participants argued that it would be easier for them to 'accept' and 'embrace' this innovation and successfully integrate it in their teaching practices. One of the participants referred to the power that educators have in boycotting innovations and ideas. Educators' feelings have to be considered regarding this innovation. Positive and negative reactions are expected to emerge. Finally, the majority of the participants positively commented on the need of students' involvement in the process of mobile devices integration. Some of the participants strongly supported that students need to have direct input on the process and the features to be developed. "I believe that they can provide valuable suggestions since they view mobile integration through a different perspective", one of the respondents commented.

Finally, the participants firmly discussed the importance of collaboration among various stakeholders. The collaboration of various stakeholders such as educators, students/ learners, computer scientists and engineers, is a critical element to successful mobile devices integration in education.

\section{DISCUSSION}

Some of the technical limitations mentioned by the participants, such as the limited storage capacities in PDAs and the battery life/charge, the lack of common operating system and common hardware platform makes, the small screen, etc; are not out of the control of a higher educational system. These are design issues that companies and designers need to consider. Regarding the limited wireless bandwidth, higher educational institutions could take care of that given the fact that in Cyprus there are the possibilities of today's cutting-edge third generation ( $3 G)$ networking technology, increasing the capacity, improving quality, and allowing the use of advanced services over the existing, Cyprus Telecommunication Authority (CYTA), GSM network. With the new $3 \mathrm{G}$ mobile devices higher education will a digital, connected learning environment will emerge and information will be provided in a compact and convenient format. Learners will have a remote and instant access to a range of people and resources as well as the ability to process data [8].

Regarding the pedagogy-oriented limitations such as the lack of knowledge regarding mobile devices integration, the need for skills development in successfully implementing mobile devices in teaching practices, the need for appropriate learning materials, instructional approaches and strategies to be applied, and educators' professional development programs; are possible to be addressed. As new technologies emerge, lecturers should be encouraged and reinforced to integrate them without hesitation nor fear. What could be done to help lecturers overcome their fears so as to absorb and utilize new technologies? In order to overcome the above mentioned limitations, the higher educational institutions could organize information- and training-days to develop the appropriate technical and pedagogical knowledge and understanding needed. Initially training seminars could be offered presenting lecturers the potential advantages that these technologies have on student learning. Further 
training with a series of hands-on experience training will reinforce lecturers with knowledge, skills, time and accessibility to mobile technologies integration.

The integration of mobile devices in several sectors of everyday life facilitates our way of living. In Cyprus, however, particularly in the area of education, we have still not benefited as the responses received show. This preliminary study has revealed that educators, who play the major role in the implementation of mobile devices in the teaching and learning process, appeared to have limited experience and knowledge on the subject. On the other hand, faculty with technical background seemed to have the basic knowledge for the technology behind mobile devices, even though they lack capabilities to integrate it into the curriculum. Furthermore, some of those who lacked basic knowledge on the subject expressed interest in learning more. Organizational, educational, and personal factors seem to influence mobile technology integration in higher education. At the moment, faculty members find it impossible to implement this new educational tool in their classes. This is mainly due to the lack of training, knowledge and skills, and, less importantly, due to the lack of the necessary infrastructure and time to learn how to integrate them. Besides all the above, it seems to be great amount of potential to integrate mobile devices in Cyprus higher education.

As previously supported there are various technological and pedagogical aspects to be considered regarding $\mathrm{m}$ learning. The new mobile learning arena imposes significant new requirements not only for the technological support and implementation but also for the educational perspective. Talking about technological challenge we mean that we must find ways to create and set up highly supportive environments which could provide support to contribute to different kind of learning settings. A technological opportunity is the fundamental transformation from the existing online learning using the advantages of $3 \mathrm{G}$ and $4 \mathrm{G}$ mobile phones and wireless communication networking.

Along the same lines, the pedagogical challenge related to m-learning is to find ways on how mobile devices can be integrated into classroom activities as well as successfully address all the parameters related to and influence mobile devices integration in education. A pedagogical opportunity is that the m-learning widens the educational horizons of students as well as enhances the educational options for educators. The categories of pedagogical aspects to be considered for successful mobile devices integration as revealed through the current study are discussed below:

1) Mobile devices applications in higher education classrooms

Mobile devices can be used by the students and the educators for professional, personal, and educational purposes. They can also be used as supportive as well as instructional tools. Mobile devices can be treated as tools to help students execute their tasks and promote the balanced development of their mental abilities by functioning as intellectual partners to the instructor and the learner.

\section{2) Curriculum and learning materials development}

Along the same lines, the need to produce innovative material that maintains a clear perspective on the learning goal is addressed [9]. As Carboni et al. mention, it is a complementary approach to the classic classroom lessons [6]. It might not be able to deliver three hour course on a PDA but is it feasible to deliver small learning activities and a number of documents, and exercises. To produce materials and design the content to be appropriate to stimulate and support the learner, knowledge of the technological constraints should exist as well. Consequently, to produce acceptable learning materials for mobile devices there is a need for educators, engineers, and computer scientists to collaborate and coordinate their actions and activities.

\section{3) Appropriate contents for mobile technology to be} used

The contents which mobile devices can be applied vary. Research so far shows that the experiments took place in various fields such as: Business and specifically MBA classes, Accounting, English, Social Studies, Mathematics, Science and Geography classes etc. Other activities include innovative games, exploring museums and exhibitions. Additionally, mobile learning devices can be used for evaluation and assessment purposes. For example, evaluate students' learning as well as assess students' attitudes to learning. Cyprus higher education (private and public) offers a variety of fields of study where mobile devices could be integrated. Educators are advised to embed and apply mobile devices in the context of teaching and learning in various contents and through various activities.

\section{4) Pedagogical methods and instructional approaches}

The authors support that there is a need for a shared, progressive pedagogy for mobile learning that will provide the scientific basis for networked and collaborative learning in both a virtual and a virtualaugmented environment. It must accommodate different teacher- and learner perspectives, promote learnercentered environments and collaboration among learners and between learners and educators. Finally, the new pedagogy must support ambient learning.

\section{5) Educators' training}

Additionally, educators need to be trained on how to apply mobile devices in their practices. To integrate computers in classroom practices, researchers were addressing the need that educators should be computer literate; in this case they have to be mobile literate. This is a great challenge because they have to deal with various types of equipment (hardware) and software. Additionally, the role of the educators needs to move towards facilitation and not teaching. With the ongoing technological advancements lecturers should gain the necessary skills through training, information and access, to overcome their fears and understand the advantages and opportunities these new technologies have to offer to their professional and personal lives.

6) Collaboration among various stakeholders: educators, students/ learners, engineers, computer scientists

Adopting an innovation is a risky process. But in order to minimize that risk and increase the success probabilities, it is important to be proactive and apply a systemic, holistic approach to mobile technology integration. The systemic approach to an innovation implies the involvement and participation of different 
parties in the design, development and implementation of the innovation. The systemic approach suggests the involvement and contribution of various stakeholders such as educators, students/ learners, engineers, computer scientists, community members, parents. The above stakeholders need to communicate, coordinate their actions, transfer and share their knowledge and experiences, as well as align their needs and goals. Educators need the help, support and knowledge of engineers and computer scientists and vice versa. It is not feasible to achieve m-learning without the coordination and knowledge integration of the above fields. Specifically, the role of the educators and the students in the design, development and implementation of the innovation is a necessity. Educators and students should be taken into consideration about the innovation and be actively involved in any steps and actions related to the integration [Kim and Holmes, 2006]. Having in mind the obstacles, failures, and problems faced when computer technology was first attempted to enter the classrooms and be established, it is extremely important to involve educators and students in this process.

\section{CONCLUSION}

Mobile technologies offer learning experiences which can effectively engage and educate contemporary learners. Although mobile technologies can be considered as computers, lecturers are hesitant to integrate them into their everyday curriculum. This research indicated that the lack of understanding and the fear about where to start in a relatively new boundary of education prevents lecturers to integrate this new tool. Lecturers need to realize the potential of mobile devices to add a new dimension to their classrooms due to their personal and portable configuration and their type of interactions they can support with other learners and the environment [33]. The challenge for lecturers is to design mobile learning opportunities that properly utilize the power, convenience, contextualization, mobility, portability, connectivity and personalization of mobile devices.

It is reasonable and expected that some researchers, educators and practitioners are wondering and trying to understand what the educational benefits from m-learning are. This concern is even more "stronger" in Cyprus since there have been made no attempts so far to integrate mobile devices in higher education. However, research showed that through mobile devices reluctant learners can be motivated, hard-to-reach learners can be reached, various skills can be developed and improved as well as better communication among learners and between learners and instructors can be achieved [2]; [9]. Consequently, there is a need for some experiments to take place in order to examine the integration of mobile devices and their effects on various parameters such as students' learning, performance, and behavior, before moving further.

In order to take full advantage and materialize the potentials that mobile integration provide us, this research proved that, before making any further attempts to integrate mobile devices in education, it is essential to develop well-defined and well-structured requirements for mobile integration in the classroom. In order to meet these requirements we need to consider parameters such as faculty and students' role, technological resources, organizational, structural and technological issues, and content design and delivery based on instructional methodologies and pedagogy. Mobile devices with advanced computing features are proliferating. They are even entering classrooms, and, before we realize it, they will probably find their ways in many educational settings just like computers did some decades ago [19].

The results of the current research work provide the basis for development and expansion of mobile devices integration in education by identifying the requirements needed for successful integration in educational systems. This work will contribute mostly to countries who still lack behind m-learning and they are willing to use this "new vehicle" for delivering education to today's learners via mobile phones PDAs, tablet PCs, etc. Higher institutions as well as educators, interested in transforming their traditional teaching/learning environment in a mobile will be introduced to challenges of mobile learning and some solutions to these challenges for a successful integration. Additionally, the results of the study prevent the danger of experiencing analogous obstacles and problems, as with computer technology integration. Since this danger is high, it is extremely important to be proactive, make wise decisions, and take appropriate actions [19]. As Wagner mentions "mobile learning represents the next step in a long tradition of technology mediated-learning" [47, p.44].

The feasibility of mobile devices integration could be further examined by focusing on other stakeholders such as students, parents, policymakers. Having evaluated the feasibility from various stakeholders, a complete set of requirements could be developed on how to successfully integrate mobile devices in higher education.

Finally, we could further expand this study by designing and implementing classroom experiments. Through experiments mobile and traditional teaching and learning processes could be compared based on various parameters such as student interaction, communication with the instructor, student performance and satisfaction.

\section{REFERENCES}

[1] Angeli, C., \& Valanides, N. (2005) A socio-technical analysis of the factors affecting the integration of ICT in primary and secondary education. In L. T. W. Hin \& R. Subramaniam (eds.) Literacy in Technology at the K-12 Level: Issues and Challenges. Heshey, PA: Education Media International.

[2] Attewell J., "Mobile learning: reaching hard-to-reach learners and bridging the digital divide," In G. Chiazzese, M. Allegra, A. Chifari, S. Ottaviano, ed., Methods and Technologies for Learning, WIT Press, Southampton, 2005.

[3] Avraamidou, L. (2008). Prospects for the use of mobile technologies in science education. AACE Journal, 16(3), 347-365.

[4] Berge L.Z., and Collins, M.P. "Computer mediated communication and the online classroom," eds. Distance learning: Volume III. Cresskill, NJ: Hampton Press, 1995.

[5] Brown, Doug (2006). Personalised learning - the technology challenge. Global Summit 2006 Technology Connected Futures. Retrieved on November $3^{\text {rd }}, 2008$ from: http://www.groups. edna.edu.au/file.php/1030/GS2006 BROWN.pdf.

[6] Carboni, et al. "Mobile Lessons and GPSWeb: mobile classrooms with goerefernced information," In: G. Chiazzese, M. Allegra, A. Chifari, S. Ottaviano, ed. Methods and Technologies for Leaning. Southampton: WIT Press, 2005, 349-353.

[7] Carr-Chellman, A.A. "Systemic Change: Critically Reviewing the literature," Educational Research and Evaluation, Vol. 4, No. 4, 1998, pp 369-394. (doi:10.1076/edre.4.4.369.6952)

[8] Clark, J. D. (2007). Learning and Teaching in the Mobile Learning Environment of the Twenty-First Century. Retrieved on 
July $15^{\text {th }}$, 2008: http://www.austincc.edu/jdclark/mobilelearni ngenables.pdf

[9] Colley, J. \& Stead, G. "Take a bite: producing accessible learning materials for mobile devices," In: J. Attewell, C. Savill-Smith, ed. Learning with mobile devices, research and development.UK: Learning and Skills Development Agency, 2003, 43-47.

[10] Council of Europe. (2004). Global education in Cyprus. The European Global Education Peer Review Process. National Report on Cyprus.

[11] Cresswell J. W., "Research Design: Qualitative, Quantitative, and Mixed Methods Approaches," $2^{\text {nd }}$ ed., Sage Publications, California, 2003

[12] Crosta,. L. "Beyond the use of new technologies in adult distance courses: an ethical approach," International Journal on ELearning, Vol. 3, No. 1, 2004, pp 48-61.

[13] Cyprus Ministry of Education and Culture. (2004). Department of Higher and Tertiary Education. Retrieved May 20, 2006, from www.moec.gov.cy.

[14] Dabbagh, N., \& Kitsantas, A. Supporting self-regulation in student-centered web-based learning environments.International Journal on E-Learning. Vol. 3, No. 1, 2004, pp 40-48.

[15] Dawabi, et al. "Using mobile devices for the classroom of the future," In: J. Attewell, C. Savill-Smith, ed. Learning with mobile devices, research and development.UK: Learning and Skills Development Agency, 2004, 55-60.

[16] Duncan-Howell, J. \& Lee, K.T. (2007). M-learning: Finding a place for mobile technologies within tertiary educational settings. In ICT: Providing choices for learners and learning. Proceedings ascilite Singapore 2007. Retrieved at November 10, 2008: http://www.ascilite.org.au/conferences/singapore07/procs/duncanhowell.pdf

[17] Eteokleous, N. (2008). Evaluating Computer Technology Integration in a Centralized Educational System. Computers and Education Journal (2007), doi:10.1016/j.compedu.2007.07.004

[18] Eteokleous, N., \& Ierodiakonou, C. (2006). Leading change in academic institutions. Published in the Proceedings of the The Commonwealth Council for Educational Administration and Management (CCEAM) Conference: Recreating Linkages between Theory and Praxis in Educational Leadership.

[19] Eteokleous, N., \& Laouris, Y. (2005). Are we Moving to Fast in Integrating Mobile Devices into Educational Practices?. In: K. Nyriri, Communications in the $21^{\text {st }}$ Century - The Mobile Information Society, 197-205.

[20] Evans, C. (2008). The effectiveness of m-learning in the form of podcast revision lectures in higher education. Computers and Education, 50, 491-498. (doi:10.1016/j.compedu.2007.09.016)

[21] Fishman, B., Soloway, E., Krajcik, J., Marx, R. \& Blumenfeld, P. (2001, April). Creating scalable and systemic technology innovations for urban education. Paper presented at the Annual Meeting of the American Educational Research Association (AERA), Seattle, Washington.

[22] Giroux, S., et al. "Mobile Lessons: Lessons Based on GeoReferenced Information," Proceedings of E-Learn 2002 Conference, World Conference on E-Learning in Corporate, Government, Healthcare and Higher Education, 2002, pp. 331338.

[23] Hadjithoma, C. (2007) New Technologies: New Schools? Embedding ICT in Primary Education: Exploring the Implementation Process in Relation to the Context and Teachers' Work (in Cyprus). PhD thesis, Graduate School of Education, University of Bristol, UK.

[24] Hewitt, J. S. M. "Design Principles for the Support of Distributed Processes," Educational Psychology Review, Vol.10, No. 1, 1998, pp 75-96. (doi:10.1023/A:1022810231840)

[25] International Bureau of Education. (2001). The development of education: National report of Cyprus. The Ministry of Education and Culture.

[26] Karagiorgi, Y. (2000) The Introduction of Educational Technology into Elementary Schoolsin Cyprus: A Critical Analysis of the Implementation of an Innovation. $\mathrm{PhD}$ thesis, Institute of Education, University of London, UK.

[27] Kim, S.H., Mims, C., \& Holmes, K.P. (2006). An introduction to current trends and benefits of mobile wireless technology use in higher education. Association for the Advancement of Computing in Education Journal, 14(1), 77-100.

[28] Krathwohl R. D., "Methods of Educational and Social Science Research: An Integrated Approach,” $2^{\text {nd }}$ ed., Longman, 1997.

[29] Kukulska-Hulme, A. (2005). Introduction. In A. Kukulska-Hulme \& J. Traxler (Eds), Mobile learning: A handbook for educators and trainers (pp. 1-8). London: Routledge.

[30] Kurubacak, G. (2007). Identifying Research Priorities and Needs in Mobile Learning Technologies for Distance Education: A Delphi Study. International Journal of Teaching and Learning in Higher Education, 19 (3), 216-227.

[31] Kvale, S. "InterViews: An Introduction to qualitative research interviewing," Thousand Oaks, CA, Sage, 1996.

[32] Milrad M. "Mobile learning: challenges, perspectives, and reality," In K. Nyiri (Ed.): Mobile learning essays on philosophy, psychology and education, Passagen Verlag, Vienna, 2003.

[33] The eLearning Guild. (2006). "Mobile Learning Research Report”, Retrieved on November $3^{\text {rd }}$. $2-8$ from: http://www.elearningguild.com/pdf/1/july 2006 mobilelearning.pdf

[34] Moustakas C. "Phenomenological Research Methods," Sage, Thousands Oaks, 2004.

[35] Naismith, L., Lonsdale, P., Vavoula, G., \& Sharples, M. (2005) Literature review in mobile technologies and learning. A report for NESTA futurelab. Retrieved October 30, 2008, from http://www.futurelab.org.uk/

[36] Pneumatikos, T. \& Michael, E. (2005). Towards the European higher education era: Bologna process - National Reports 20042005. Department of Higher and Tertiary Education. Ministry of Education and Culture.

[37] Polsani P. "Network learning," In K. Nyiri K. (Ed.): Mobile learning essays on philosophy, psychology and education, Passagen Verlag, Vienna, 2003.

[38] Quinn, C., M-Learning: Mobile, Wireless, In-Your-Pocket Learning, LiNE Zine, 2000

[39] Republic of Cyprus (1999) Annual report on education 1999, Ministry of Education and Culture, Nicosia.

[40] Rist R. D., "On the application of ethnographic inquiry to education: Procedures and Possibilities", Journal of Research in Science Teaching, 1982, vol. 19, pp. 439-450. (doi:10.1002/tea. 3660190602)

[41] Seppala, P., \& Alamaki, H. (2003). Mobile learning in teacher training. Journal of Computer Assisted Learning, 19(3), 330-335. (doi:10.1046/j.0266-4909.2003.00034.x)

[42] Swett, C. (2002, October). College students' use of mobile wireless-internet connections becomes more common. Knight Ridder Tribune Business News, Washington, DC.

[43] Trifonova, A. and Ronchetti, M. "Prepare for a bilingualism exam with a PDA in your hands," In: G. Chiazzese, M. Allegra, A. Chifari, S. Ottaviano, ed. Methods and Technologies for Leaning. Southampton: WIT Press, 2005, 343-347.

[44] Turban E., McLean E., and Wetherbe J. "Information Technology For Management: Transforming Organizations in the Digital Economy," John Wiley\& Sons, inc, 2004.

[45] Turunen H., Syvaenen A., Ahonen M., Supporting observation tasks in a primary school with the help of mobile devices, In $\mathrm{K}$ Nyvri (Ed.), Mobile learning: essays on philosophy, psychology and education, Communications in the 21st Century, Passagen Verlag, Vienna, 2003.

[46] Vrasidas, C. (2002). Educational technology in Cyprus and strategies for higher education. Education Media International, 39, 123-131. (doi:10.1080/09523980210153462)

[47] Wagner, E. D. (2005). Enabling mobile learning. EDUCASE, May/June 2005, 41-52.

[48] Zurita, G., \& Nussbaum, M. (2004). A constructivist mobile learning environment supported by a wireless handheld network. Journal of Computer Assisted Learning, 20, 235-243. (doi:10.1111/j.1365-2729.2004.00089.x) 


\section{AUTHORS}

N. Eteokleous is with the Frederick University Cyprus, Yianni Frederickou, Str., POBox 24729, Nicosia 1303, Cyprus (e-mail: nikleia@cytanet.com.cy).

D. Ktoridou is with the University of Nicosia, 46, Makedonitissas Ave., P.O. Box 240051700 Nicosia, Cyprus (e-mail: ktoridou@cytanet.com.cy).

Manuscript received 9 December 2008. Published as submitted by the authors. 